\title{
A simple classification and a simplified treatment's algorithm for ptotic breasts
}

\author{
Bouraoui Kotti \\ Plastic Surgery Department, Medical School of Tunis, Tunis 1007, Tunisia.
}

Correspondence to: Dr. Bouraoui Kotti, Résidence "Yasmin du lac" Bloc A, Stock exchange avenue, Lake 2, Tunis 1053, Tunisia. E-mail:contact@drkotti.com

How to cite this article: Kotti B. A simple classification and a simplified treatment's algorithm for ptotic breasts. Plast Aesthet Res 2018;5:16. http://dx.doi.org/10.20517/2347-9264.2018.11

Received: 24 Feb 2018 First Decision: 4 Apr 2018 Revised: 8 Apr 2018 Accepted: 10 Apr 2018 Published: 25 Apr 2018

Science Editor: Umar Daraz Khan Copy Editor: Guang-Zhe Zhu Production Editor: Cai-Hong Wang

\begin{abstract}
Aim: Many classifications have been described in the literature for ptotic breasts, focusing on the nipple areola complex position compared to the inframammary fold. These use centimeters and lateral views to illustrate their various grades in a manner always insufficient to propose a clear treatment plan aimed at achieving natural results. We discuss a new dynamic approach to breast ptosis with a complete treatment algorithm.
\end{abstract}

Methods: Patients were examined in a standing position first with hands down then with hands up. We observed the elevation of the inter-nipple line called the "BK-line" and its relationship to a sternal benchmark that we call the "BKPoint". The "hands-up test" was positive when the line crossed the landmark. The algorithm defines the indication according to this clinical examination and to the patient's wishes. An angle between the nipple, the "BK-point" and the body meridian (called the "BK angle") was appreciated before and after surgery. This angle should become $90^{\circ}$ or more after ptosis treatment.

Results: Three hundred patients were treated for ptotic breasts, including breast reductions, from January 2010 to September 2017. The definitions of "normal" non-ptotic and ptotic breast and the "ideal" breast were reconsidered. The surgical indications were adjusted to the clinical situation and to the patient's wishes, refining the final version of the algorithm.

Conclusion: This new classification is easy, reproducible and efficient. We propose an appropriate algorithm to treat every situation that takes care to consider patient's wishes and expectations.

Keywords: Breast ptosis, mammoplasty, vertical lift, mastopexy, breast reduction, breast implant, ptosis classification

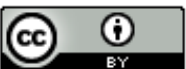

(C) The Author(s) 2018. Open Access This article is licensed under a Creative Commons Attribution 4.0 International License (https://creativecommons.org/licenses/by/4.0/), which permits unrestricted use, sharing, adaptation, distribution and reproduction in any medium or format, for any purpose, even commercially, as long as you give appropriate credit to the original author(s) and the source, provide a link to the Creative Commons license, and indicate if changes were made.

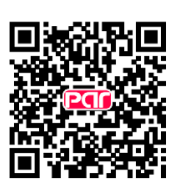




\section{INTRODUCTION}

The female breast is one of the rare anatomical organs that has no bony or cartilaginous supports. Suspended to the trunk by its soft structures, the final shape is substantially influenced during growth by the bone, cartilage and muscle elements that surround the breast's bases. For an adult woman, the "perfect" match of a glandular tissue, fat, skin and connective tissue that hold everything in place may theoretically give rise to a "perfect breast". The natural or pathologic excess of one of these anatomical tissues may lead to breast sagging, or what we call breast ptosis.

Time and gravity also affect the breast and induce glandular and skin stretching, especially in the periareolar area and in the lower pole where weight is maximal. In addition to the anatomical comprehension of this auto-suspended organ, the aesthetic and social representation of the sexual organ defined over centuries, including through artwork, provided guidelines for ideal measurements of the "perfect breast", as well as various classifications for ptotic breasts.

In this paper we will revisit the primary classifications we were taught during training, to ascertain their inadequacies and to propose a new simple classification with a treatment algorithm that also takes the patient's wishes into account.

\section{METHODS}

We consider two important landmarks:

1. The sternal landmark is a single point on the sternum where the inframammary folds, or their extensions, cross the midline. We call it the Breast Key point or "BK-Point" [Video 1].

2. The inter-nipple line or Breast Key line: "BK-line" is a virtual line joining the nipples for which we have to restore the horizontality in case of an asymmetry, and make it cross the BK-point after treating the ptosis [Video 2].

We examine the patient in a standing position hands down along the body in frontal, oblique and lateral views and take photos for preoperative analysis and as a reference for the post-operative check.

We ask the patient to put her hands up and note the BK-line ascent and its eventual crossing of the BK-point.

Photos are also taken as a reference and are saved in the patient's file.

The second examination was completed on the screen with an oblique view photo. We appreciated the angle between the ipsilateral nipple to body rotation (right nipple to right oblique view and vice-versa), and the BK-point and body meridian usually parallels the dorsal spine. We call this angle the Breast Key (BK) angle, and we roughly appreciate its value compared to a right angle.

Our approach is simple:

With a patient's hands down, there is no ptosis if the BK-line crosses the BK-point.

A "natural ptosis" exists when this match occurs after asking a patient to put her hands up. We call this maneuver a "hands up test" positive.

A "confirmed ptosis" is defined when the BK-line remains under the BK-point with a hands-up maneuver. We call this a negative "hands-up test" [Figure 1] [Videos 3 and 4]. 


\section{Hands' up test}

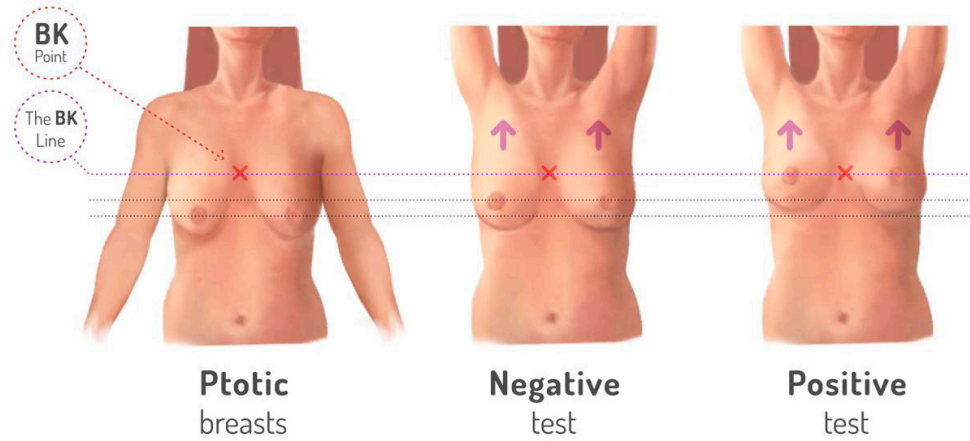

Figure 1. The "hands-up test" maneuver

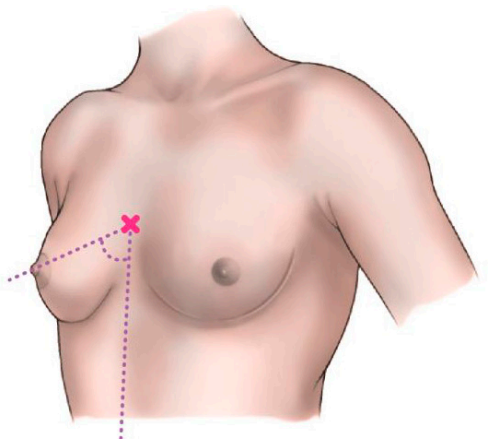

Ptotic Breast

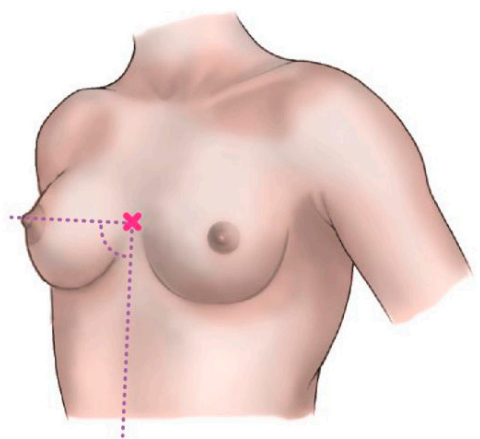

Non Ptotic Breast

Figure 2. The BK angle appreciation

The BK-angle is less than $90^{\circ}$ in case of a ptotic breast and becomes $90^{\circ}$ or more after successful ptosis treatment [Figure 2].

\section{RESULTS}

From January 2010 to September 2017, 300 patients presenting for breast lift, mastopexy or breast reduction were analyzed and treated with various surgical techniques. The first aim was ptosis treatment and the second was to satisfy the patient's wishes; at the surgeon's suggestion, augmentation or reduction of the volume, or sometimes the redefinition of the breast shape was undertaken. Gigantomastia and important asymmetries including Poland's syndrome, oncologic breast surgery and tuberous breasts were excluded from this study.

From this experience and from various clinical observations, an algorithm was proposed for every situation in our classification [Figure 3] and some representative cases were illustrated [Figures 4-7].

\section{DISCUSSION}

A quick look at two mythic Venuses throughout the history of art: the Venus of Willendorf [Figure 8] and the Venus de Milo [Figure 9], shows us substantial evidence of the evolution of the criteria for aesthetic beauty 


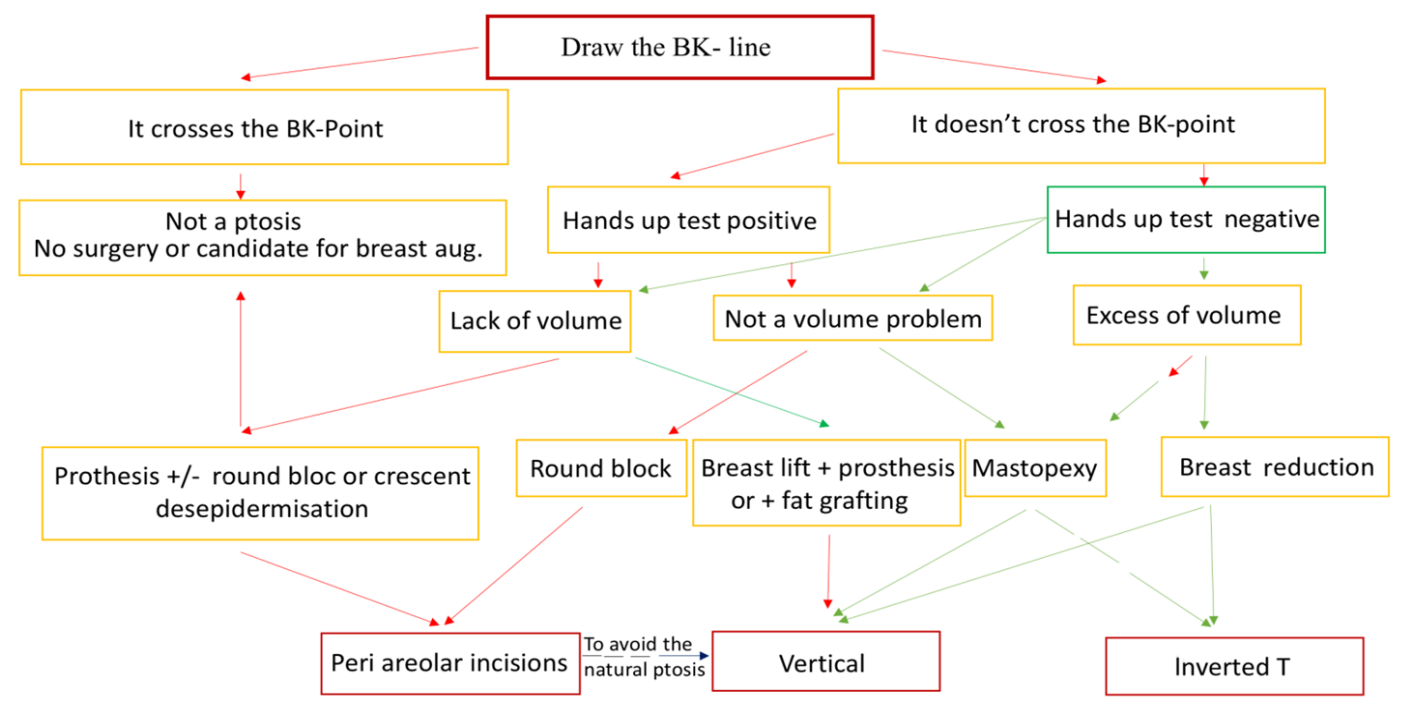

Figure 3. Algorithm for the ptotic breasts' treatment
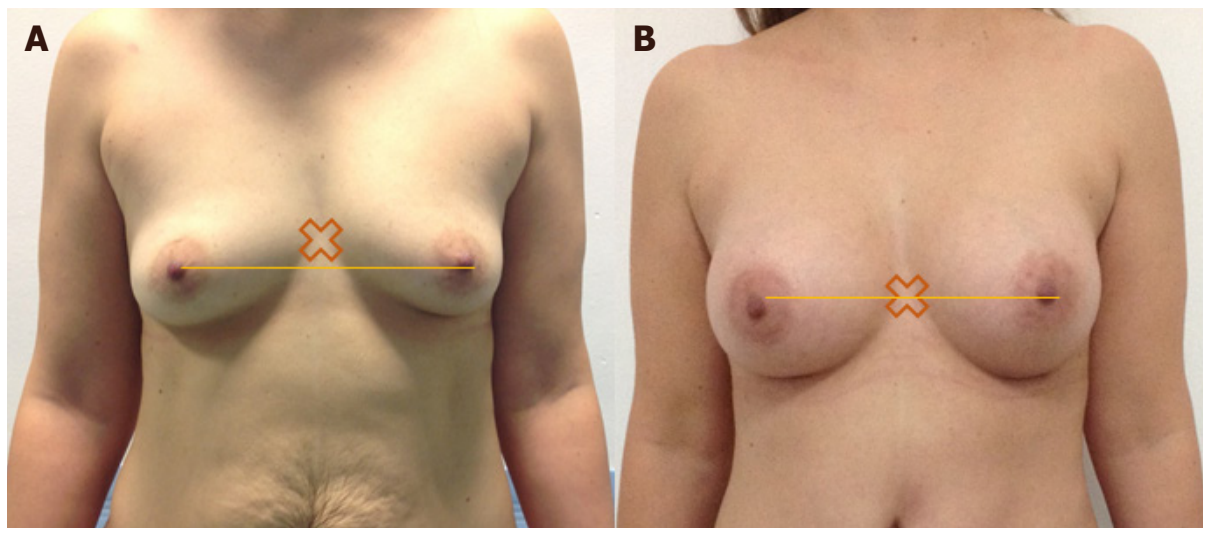

Figure 4. (A) Small ptosis after breast feeding with a hands up test positif; (B) a simple breast augmentation can restore the lost volume during a mommy makeover procedure and allows the ptosis treatment

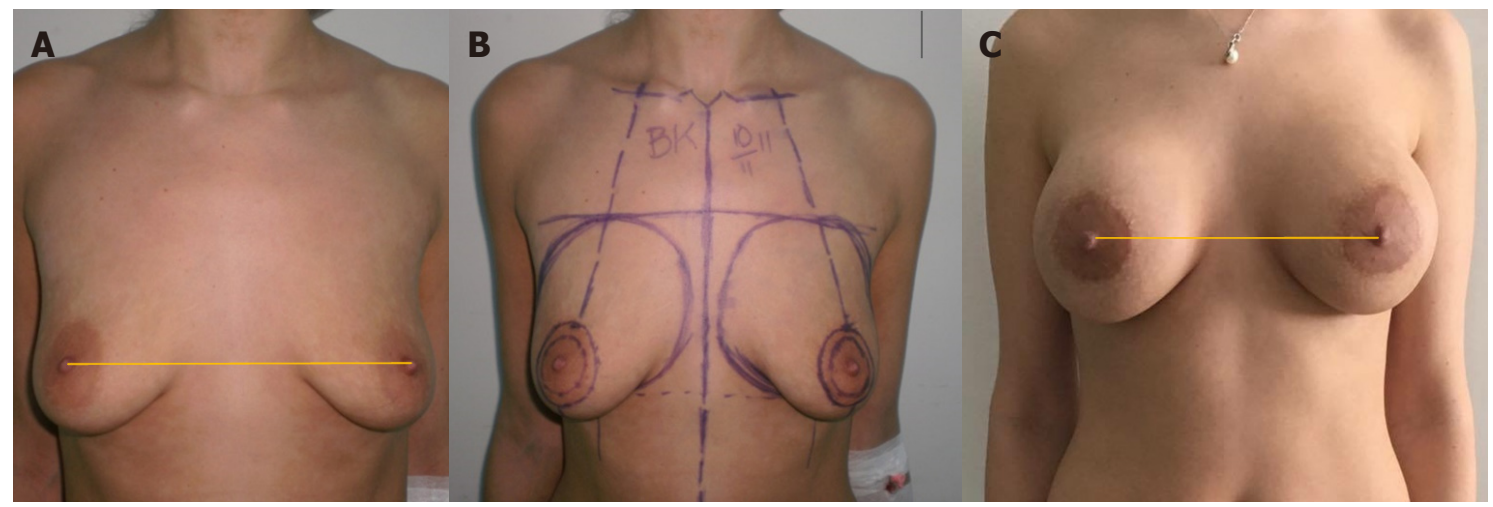

Figure 5. (A) A 25-year-old woman asking for a breast augmentation. The distribution of the glandular tissue and the apparent "dysmastia" with an external position to the midline of the IMF may explain the eventual ptosis effect. The BK line is still crossing the BK point; (B) a round block approach with a $450 \mathrm{~mL}$ round silicone implants in a dual plane were performed; (C) a stable result after 4 years and 2 pregnancies 

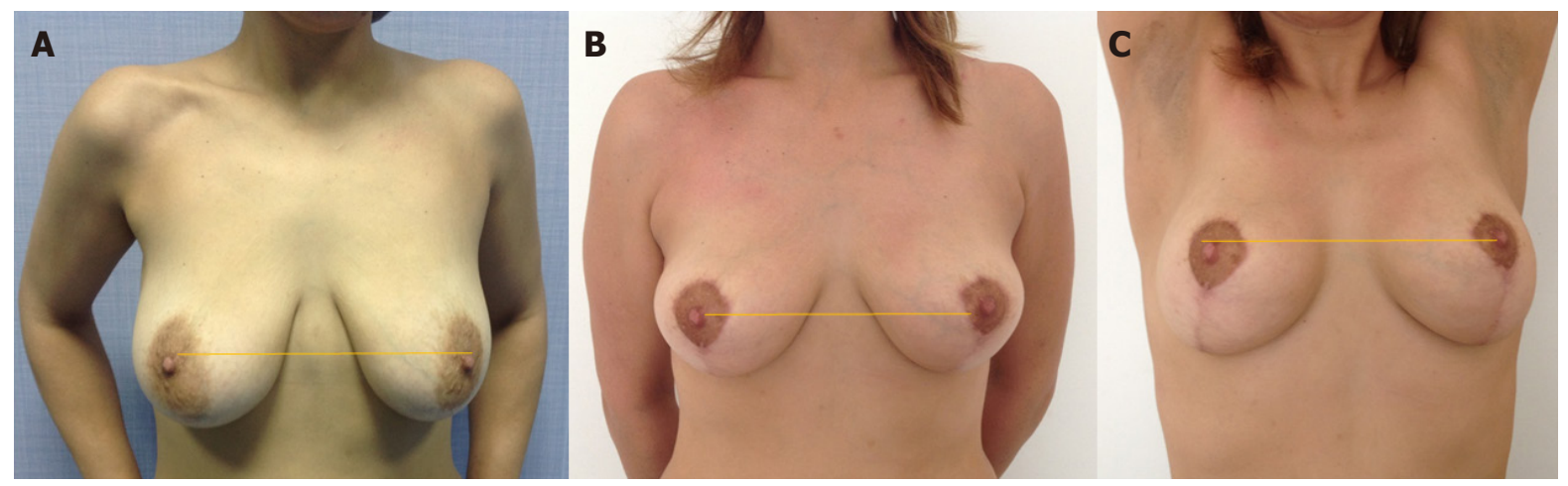

Figure 6. (A) A 35-year-old woman asking for a breast ptosis treatment with a natural look. Implants and fat grafting were discussed and rejected by the patient insisting to have a natural result; (B) a "chignon mastopexy" was performed keeping, after a year, a minor ptosis for a natural effect; (C) this ptosis is giving, according to our approach, a natural breast look and of course this ptosis is corrected with a hands up test

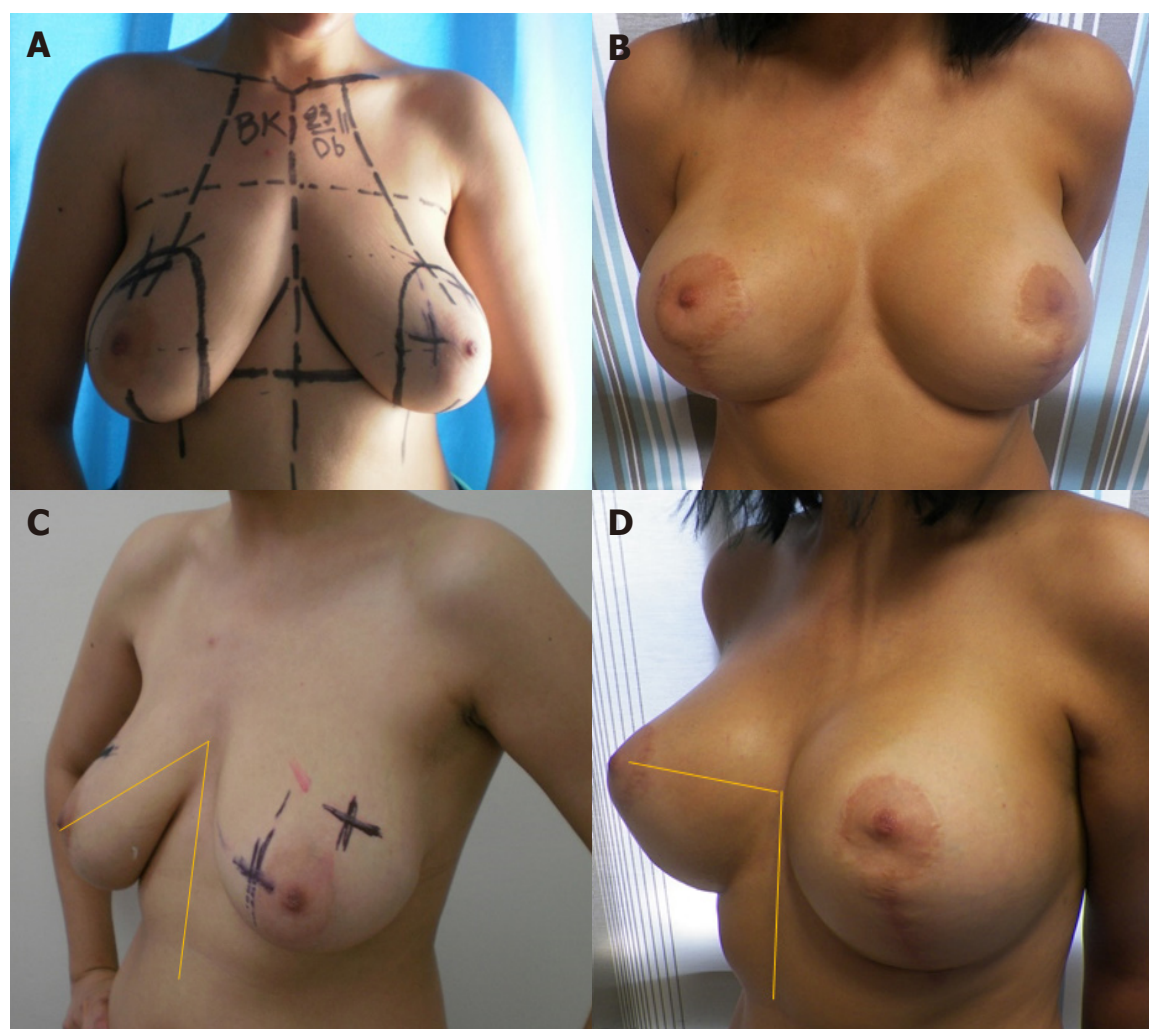

Figure 7. (A) A 30-year-old woman with an important ptosis and multiple nodules asking for a breast lift and a minor volume augmentation as well as a "push-up effect"; (B) a vertical breast lift approach was performed with multiple fibroadenomas resections. A 320 round and moderate profile silicone implants were added before the final cutaneous lift. Here, we did not opt for a natural breast ptosis effect and directly restored the BK line to the BK point level; (C) and (D) note also that the BK angle is deliberately pulled up to more than $90^{\circ}$ to confirm this "push up effect"

of the female body; from enlarged and ptotic breasts symbolizing good health and perhaps breastfeeding in a mother goddess, to a small, non-ptotic and athletic breast symbolizing femininity (as well as good health) in a goddess of love and beauty ${ }^{[1,2]}$. Breast ptosis is no longer in vogue.

The definition of a ptotic breast remains controversial even if currently the standards are more or less common among continents, societies and tribes. The complexity of this task, especially for proposing 


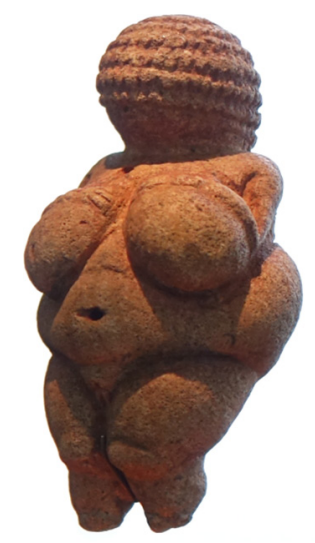

Figure 8. Venus of Willendorf

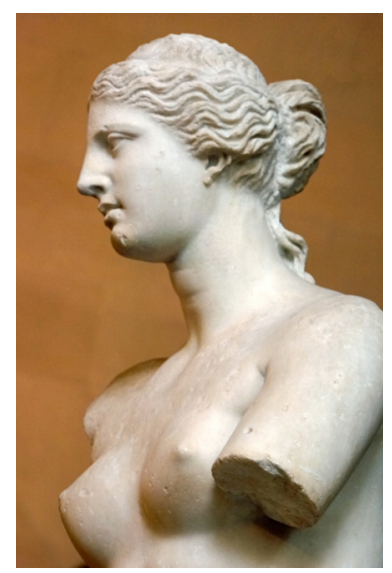

Figure 9. Venus of Milo

surgical treatments, has been exposed by a number of publications and classifications of ptotic breasts since Dufourmentel and Mouly's book in $1959^{[3]}$.

Dufourmentel and Mouly defined ptosis by the dropping of the nipple down and out using " $5 \mathrm{~cm}$ " as a level unit to switch from a grade to another ${ }^{[3]}$, while Lalardrie and Jouglard chose the inframammary fold (IMF) as a benchmark to measure the fall of the lowest point of the breast using 2 and then $4-10 \mathrm{~cm}$ as the levels at which grades switch ${ }^{[4,5]}$. They also reported a change in the form of segment II, normally convex according to their interpretation and becoming straight and then concave with ptosis.

A normal natural breast in our observations will never have a spontaneously convex segment 2; this remains an effect of a push-up or a surgical procedure.

Regnault ${ }^{[6]}$ proposed one of the most common classifications to date, using a combination of these two former classifications while taking the nipple, the IMF and the lowest point on the breast as landmarks to define various grades as well as the "normal breast", "pseudo ptosis" and "parenchymal maldistribution".

By avoiding the use of numbers and centimeters and the individualization of two extra different types involving the glandular distribution during the breast development, Regnault ${ }^{[6]}$ proposed a wide and wise clinical observation of the various types of breasts, explaining the popularity of this classification worldwide. 


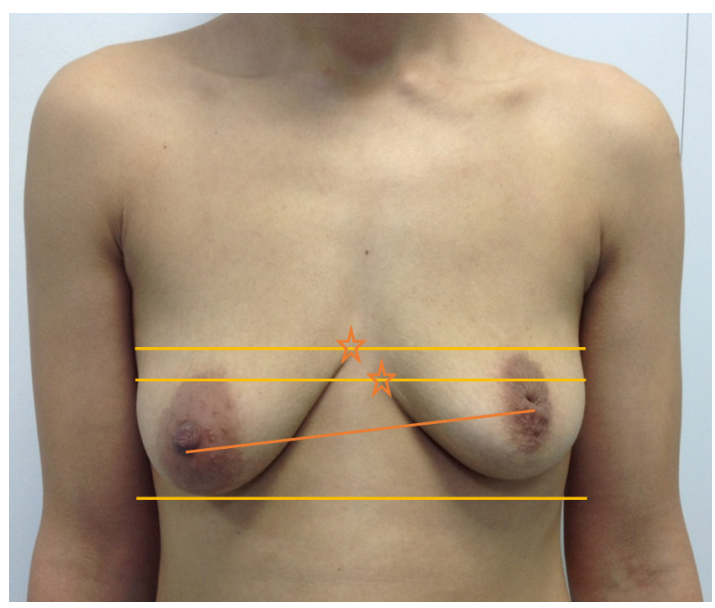

Figure 10. Example of an asymmetry with an offset definition of the Inframammary fold: The stars show different positions of the inframammary folds reaching the midline; the BK point in this case will be the upper one and the ptosis treatment will aim to horizontalize the BK line and make it crossing the BK point

Even if we totally adhere to Regnault ${ }^{[6]}$ to individualize "parenchymal maldistribution" that we also excluded from our classification, we do not agree with the definitions of "normal breast", "true" or "pseudo-ptosis". In fact, what is "normal" for Regnault ${ }^{[6]}$ is a "perfect breast" for us, as we consider that a normal breast may also have a small ptosis regressing with a "hands up test" positive. Conversely, this small ptosis may express desirable femininity in some cultures; many Asian women, in order to prove their mature femininity, waged a hashtag campaign called \#carrypenunderbreast that went viral on social media, demonstrating that a glandular parenchymal distribution under the IMF is, for the majority of people, a desired target in the Eastern hemisphere and also a normal shape in Western countries.

"Pseudo-ptosis" considers the sagging of the parenchyma despite the nipple position remaining above the IMF without taking regard to the high or low position of the IMF. Indeed, this crease is a curved line, usually starting from the anterior axillary line to the sternal area with a different attachment and a different direction from one patient to another, and sometimes from one breast to another for the same woman [Figure 10]. Using it as a landmark is a shortcoming of the Regnault ${ }^{[6]}$ classification, as well as the one proposed a year later by Vandenbussche ${ }^{[7,8]}$ and even later reconfirmed in the literature by including a physiological approach to each of the four new grades described by the same author.

Robert Brink confirmed this physiological necessity to explain ptosis one year after Vandenbussche's paper $^{[7,8]}$ by proposing a different classification in his work, and a variation of the "Round Block" periareolar mastopexy approach to the "true ptosis concept" ${ }^{\text {"[?] }}$.

In our approach, we always analyze the physiology of breast sagging for each patient but never nest it within a treatment diagram. We believe that defining a true and a pseudo-ptosis is unfit for a decision-making process as confirmed by Kirwan's vision ${ }^{[10]}$.

Nevertheless, despite the detailed and pragmatic algorithm proposed by this author, we do not agree with the use of centimeters as a way of measurement to differentiate one proposed alphabetic grade from another. In fact, we believe that " $1 \mathrm{~cm}$ " on the breast is different from one woman to another according to the skeleton and to the phenotype of each body, and that the classification of the breast and the diagnosis of the ptosis have to be defined in an overview and designed in a frontal view (never on a lateral view).

In Figure 5 we elaborated an algorithm that respects the surgeon's training and preferred technique in order to globalize the clinical and surgical approach to the primary task of breast ptosis treatment. Even if we 
usually prefer a less-invasive approach to each case with as few scars as possible, by privileging the round block technique as described by Benelli ${ }^{[1]}$ or by $\operatorname{Brink}^{[9]}$ (with unfortunate rapid limitation of its use ${ }^{[12]}$ ), deliberately or not, there would be preservation of "natural ptosis" corrected with a "hands up test" positive or enlargement of the round scar. Therefore, we prefer the vertical approach for a breast lift, as described by Lassus ${ }^{[13]}$, or mastopexy using the chignon technique as described by Kotti ${ }^{[14]}$ instead of the inverted $\mathrm{T}$ approach. However, as we believe that our algorithm must respect the patient's wishes as to final volume, the final scars and the respect of the presence or absence of a natural ptosis, we also believe that it must respect the surgeon's training and the diversity of the effective surgical procedures described in the literature to find final balance that serves the cause of the ptosis treatment and respects a universal beauty criterion.

We propose a classification that is:

- Simple: without measurements,

- Reproducible: with a simple clinical maneuver without the use of any special devices and,

- Efficient: the breast is analysed in a frontal view, not lateral views, as it is seen in daily social life.

We also propose an appropriate treatment algorithm for every situation that takes the patient's wishes and expectations into account and obeys plastic surgery principles without excluding any surgical technique in order to adapt to the various surgeons' approaches and preferable procedures.

\section{DECLARATIONS}

\section{Authors' contributions}

The author contributed solely to the paper.

\section{Data source and availability}

The data presented is original and obtained in our laboratory. It is available with the authors and can be made available if required.

\section{Financial support and sponsorship}

None.

\section{Conflicts of interest}

There are no conflicts of interest.

\section{Patient consent}

Consents from all of the patients were established prior to submission.

\section{Ethics approval}

All treatment and study were performed in compliance with our institutional standard and the Declaration of Helsinki.

\section{Copyright}

(c) The Author(s) 2018.

\section{REFERENCES}

1. Seshadri KG. Obesity: a Venusian story of Paleolithic proportions. Indian J Endocrinol Metab 2012;16:134-5.

2. Zygmont BJ. Venus of Willendorf. Available from: http://smarthistory.org/venus- of-willendorf [Last accessed on 12 Apr 2018].

3. Dufourmentel C, Mouly R. Chirurgie plastique. Paris: Flammarion; 1959. p. 327-70.

4. Lalardrie JP, Jouglard JP. Chirurgie plastique du sein. Paris: Masson; 1974. p. 290. 
5. Lalardrie JP, Jouglard JP. Reduction mammoplasty: general approach and basic considerations. Aesthetic Plast Surg 1982;6:81-3.

6. Regnault P. Breast ptosis. Definition and treatment. Clin Plast Surg 1976;3:193-203.

7. Vandenbussche F. Chirurgie plastique mammaire: indications, possibilités et limites. Lille Med 1977;22:572-5.

8. Vandenbussche F. Ptôse mammaire: classification et sommaire des indications chirugricales. Ann Chir Plast Esthét 1992;37:218-26.

9. Brink RR. Management of true ptosis of the breast. Plast Reconstr Surg 1993;91:657-62.

10. Kirwan L. A classification and algorithm for treatment of breast ptosis. Aesthet Surg J 2002;22:355-63.

11. Benelli L. A new periareolar mammaplasty: the "round block" technique. Aesthetic Plast Surg 1990;14:93-100.

12. Fogli A. Indications and limitations of breast lifting by peri-areolar approach (round block). Report of 48 cases. Ann Chir Plast Esthet 1990;35:459-69.

13. Lassus C. A 30-year experience with vertical mammaplasty. Plast Reconstr Surg 1996;97:373-80.

14. Kotti B. The "Chignon Mastopexy": a double glandular suspended flaps for an auto-augmentation effect. Aesthet Plast Surg 2018;42:80-7. 